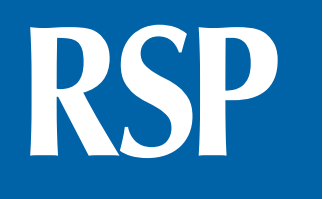

http://www.rsp.fsp.usp.br/
Revista de Saúde Pública

\section{COVID-19 and mental health of pregnant women in Ceará, Brazil}

\author{
Márcia Maria Tavares Machado' (iD, Hermano Alexandre Lima Rocha',"l (iD, Marcia C. Castro" (iD, \\ Edgar Gomes Marques Sampaio' (iD, Francisco Ariclene Oliveira' (iD), Jordan Prazeres Freitas da \\ Silva' (iD, Camila Machado de Aquino"'I iD, Liduina de Albuquerque Rocha de Sousa"'I (iD, \\ Francisco Herlanio Costa Carvalho'II iD, Elisa Rachel Pisani Altafimv iD, Luciano Lima Correia' \\ I Universidade Federal do Ceará. Faculdade de Medicina. Departamento de Saúde Coletiva. Fortaleza, CE, Brasil \\ " Harvard TH Chan School of Public Health. Department of Global Health and Population. Boston, MA, USA \\ III Universidade Federal do Ceará. Faculdade de Medicina. Departamento de Saúde Materno-Infantil. Fortaleza, \\ CE, Brasil \\ Iv Fundação Maria Cecilia Souto Vidigal. São Paulo, SP, Brasil
}

\section{ABSTRACT}

OBJECTIVE: To assess the perceptions of pregnant women about COVID-19 and the prevalence of common mental disorders during the implemented social distancing period.

METHODS: This was an observational, cross-sectional study using digital media, of pregnant women exposed to social distancing due to the COVID-19 pandemic, in Fortaleza, Ceará, Northeastern Brazil. Common mental disorders were estimated using the modified Self-Report Questionnaire-20 (SRQ-20) scale, and the feelings towards COVID-19 were assessed using the Fear of COVID-19 scale through telephone calls made in May 2020. COX multivariate regression models were used to verify the associations.

RESULTS: Of the 1,041 pregnant women, 45.7\% (95\%CI: 42.7-48.8) had common mental disorders (CMD). All items of the Fear of COVID-19 Scale showed a significant association with the prevalence of CMD $(\mathrm{p}<0.001)$. A CMD risk gradient was observed, going from a prevalence ratio of 1.52 (95\%CI: 1.13-2.04) in pregnant women with two positive items to 2.70 (95\%CI: 2.08-3.51) for those with four positive items. Early gestational age and the lack of prenatal care were also associated with CMD.

CONCLUSIONS: The prevalence of common mental disorders in pregnant women was high during the period of social distancing and was aggravated by negative feelings towards COVID-19.

DESCRIPTORS: Pregnant Women. Coronavirus Infections, psychology. Mental Disorders. Social Isolation.
Rocha HAI Castro MC Sampaio EGM, Oliveira FA, Silva JPF, et al. COVID-19 and mental health of pregnant women in Ceará, Brazil. Rev Saude Publica. 2021;55:37. https://doi.org/10.11606/

s1518-8787.2021055003225

Copyright: This is an open-access article distributed under the terms of the Creative Commons Attribution License, which permits unrestricted use, distribution, and reproduction in any medium, provided that the original author and source are credited. 


\section{INTRODUCTION}

The global pandemic of Coronavirus Disease-19 (COVID-19), declared by the World Health Organization (WHO) on March 11, 2020, has already surpassed 32 million cases and 984,590 deaths worldwide'. Official data from Brazil, as of September 25, 2020, have recorded 4,657,702 confirmed cases of COVID-19, with 139,808 deaths, resulting in a case-fatality rate of 3.0\%². Moreover, of the 52,335 hospitalizations due to COVID-19, 521 (1.0\%) were of pregnant women, of which 36 died.

Social distancing measures were implemented in many cities in Brazil to mitigate COVID-19 expansion. These measures were associated with an increased prevalence of anxiety in pregnant women, especially during the first trimester of pregnancy ${ }^{3}$. Pregnancy and the postpartum period have been identified as risk factors for the development and exacerbation of mental health problems ${ }^{4}$. Common mental disorders (CMD) in this population group include depression, generalized anxiety disorder, panic disorder, phobias, social anxiety, obsessive-compulsive disorder and post-traumatic stress disorder ${ }^{5}$. The worldwide prevalence of CMD in the population reaches $29.2 \%$. In a Brazilian study with 330 pregnant women, conducted before the coronavirus pandemic, CMD outcome had a $57.1 \%$ prevalence, being associated with marital status, gestational age, planned pregnancy and bleeding .

In situations of anxiety and depression, high levels of substances such as adrenaline and dopamine are produced, both responsible for stress reactions ${ }^{7}$. The presence of CMD during pregnancy is associated with obstetric outcomes such as miscarriage, preterm birth and low birth weight, shorter duration of exclusive breastfeeding, growth deficit, and possible child developmental delay ${ }^{4,8,9}$.

Studies on the influence of the COVID-19 pandemic on the mental health of pregnant women are scarce ${ }^{10}$. This is the first study conducted in a low-income context, in the Northeast of Brazil, aiming at assessing perceptions of pregnant women regarding COVID-19 and its effect on the prevalence of CMD during the social distancing period and at identifying possible socioeconomic and health determinants.

\section{METHODS}

This was an observational, cross-sectional study, conducted with pregnant women exposed to social distancing due to the COVID-19 pandemic, in the city of Fortaleza, state of Ceará, Northeastern Brazil, to assess the effects of social distancing on the mental health of these women. The recommendations established by the Strengthening the Reporting of Observational Studies in Epidemiology - STROBE ${ }^{11}$ - were adopted.

After approval by the National Research Ethics Committee and the acceptance of the informed consent form, all pregnant women residing in the six regions of the municipality of Fortaleza, who were subjected to social distancing measures, were considered eligible. The exclusion criteria consisted of pregnant women with a diagnosis of malformation or another severe fetal disease, and pregnant women with severe pregnancy complications that could significantly affect their mental health.

Data collection started on April 21, 47 days after the beginning of the social distancing decree, and finished on May 2, 2020. An online questionnaire with 49 closed questions created on the Google Forms platform was used. The questionnaire was distributed through a link via an instant messaging application and included questions on women's profile, mental health (anxiety, fear), and feelings about the social distancing period. The average time to fill out the questionnaire varied from 5 to 10 minutes.

The presence of CMD was estimated by 9 of the 20 items that comprise the SRQ-20 (Self-Reporting Questionnaire) ${ }^{12}$, including somatic symptoms (has unpleasant sensations 
in the stomach, poor digestion, lack of appetite, frequent headaches), depressed mood (has been crying more than usual, has been feeling sad lately), and depressive thoughts (feels like a useless/worthless person, unable to play a useful role in their life, has lost interest in things). Nine items of the scale were used because some questions were considered a potentially risky to trigger a pre-existing depressive condition (e.g., questions about suicidal ideation, the desire to take one's life, among others) in a scenario in which direct assistance to the respondent was not feasible. The SRQ-20 result classifies respondents into positive cases of depression when the sum of the scores is higher than 7; that is, more than $35 \%$ of positive responses. Thus, to adjust the outcome to this new application, we used the same proportion for the 9-item scale, created by separating the group into tertiles, in which the last tertile was considered to be of high risk for common mental disorders (scores higher than four).

The Fear of COVID-19 Scale ${ }^{13}$ instrument was used to assess negative feelings regarding COVID-19 among pregnant women (e.g., "I feel uncomfortable when thinking about Coronavirus", "I am very afraid of Coronavirus", "I cannot sleep because I am worried about getting the Coronavirus", and "when I watch the news and stories about COVID-19 on social media I get nervous or anxious"). Participants were classified as having between none up to 4 negative feelings. Socioeconomic and demographic variables self-reported by pregnant women were also collected, including age, education, working pattern, participation in cash transfer programs, use of health services, family composition and conditions of pregnancy.

\section{Statistical Analysis}

To describe the sample characteristics, absolute and relative frequencies of nominal variables were estimated, as well as mean and standard deviation of quantitative variables. In a bivariate analysis, the Chi-square test was used to verify the independence between explanatory variables and CMD. Variables that showed a descriptive level $<0.20$ in the bivariate analysis were used for controlling possible confounding effects in a multivariate regression model. Cox Regression was chosen because, as compared to Poisson regression, it presented more robust results. As Cox regression was originally created for survival analysis, its use in cross-sectional data requires adjustment of variances and considering the time measurement as the same for all individuals $(t=1)$, as was proceeded in our study $^{14}$. Logistic regression analysis was not appropriated for this data due to the highly frequent outcome producing odds overestimation. Crude and adjusted prevalence ratios were estimated together with their respective confidence intervals. A forest plot chart was built using the Cox model measures of effect. The magnitude of the associations found at a significance level of $p<0.05$ was expressed as measures of the prevalence ratio. The data were analyzed using IBM SPSS software, version 24.

\section{Ethical Approval}

Project was approved by the Ethics Committee of the Universidade Federal do Ceará, No. 4.043.259, May 2020. The authors have obtained both informed consent and ethics committee approval for studies on volunteers. The women interviewed answered the questionnaire, sent online, during the period of social distance. Before answering the questionnaire, the consent form was made available when the interviewee answered if she accepted to participate in the research.

\section{RESULTS}

Data were collected from 1,041 pregnant women, whose ages ranged from 16 to 48 years, with a mean age of 31.3 years. The median per capita income of the participants was US\$ 500.26. Most participants (80.5\%) reported having more than 12 years of schooling and only about $5 \%$ of them were beneficiaries of the government's cash transfer program. 
Less than $33 \%$ lived in a household with more than three residents. In total, 476 (45.7\%) were classified as having a CMD, and $60.6 \%$ had three or four positive questions on the anxiety scale related to COVID-19 (Table 1).

All items selected from the Fear of COVID-19 Scale instrument showed a statistically significant association with the prevalence of CMD individually $(\mathrm{p}<0.001)$, and the item showing the strongest association was "I feel uncomfortable when thinking about the Coronavirus", with a prevalence 1.87-fold higher in pregnant women with CMDs (95\%CI: 1.43-2.44). The cumulative number of positive items on the scale of negative

Table 1. Characteristics of pregnant women included in the study $(n=1,041)$. Fortaleza, Brazil, 2020.

\begin{tabular}{|c|c|c|c|}
\hline \multicolumn{2}{|l|}{ Variable } & \multirow{2}{*}{$\frac{\mathbf{n}}{837}$} & \multirow{2}{*}{$\begin{array}{c}\% \\
80.4\end{array}$} \\
\hline \multirow{2}{*}{ Age range } & Up to 35 years & & \\
\hline & $>35$ years & 204 & 19.6 \\
\hline \multicolumn{2}{|l|}{ Median (IQR) income per capita (US\$) } & \multicolumn{2}{|c|}{$500.26(316.96-1,009.25)$} \\
\hline \multirow{3}{*}{ Marital status } & Married or common-law marriage & 921 & 88.5 \\
\hline & Widowed/Divorced/Separated & 16 & 1.5 \\
\hline & Single & 104 & 10.0 \\
\hline \multirow{4}{*}{ Education } & Middle School or less & 7 & 0.7 \\
\hline & High School & 196 & 18.8 \\
\hline & College/University & 397 & 38.1 \\
\hline & Postgraduate & 441 & 42.4 \\
\hline \multicolumn{2}{|c|}{ Participates in the government's cash transfer programs } & 51 & 4.9 \\
\hline \multirow{6}{*}{$\begin{array}{l}\text { N. of people living with the pregnant } \\
\text { woman }\end{array}$} & Lives alone & 10 & 1.0 \\
\hline & 1 & 341 & 32.8 \\
\hline & 2 & 299 & 28.7 \\
\hline & 3 & 211 & 20.3 \\
\hline & 4 & 108 & 10.4 \\
\hline & 5 or more & 72 & 6.9 \\
\hline \multirow{9}{*}{ Items of the SRQ scale: } & $\begin{array}{l}\text { 1. Do you have unpleasant sensations } \\
\text { in your stomach? }\end{array}$ & 466 & 44.8 \\
\hline & $\begin{array}{l}\text { 2. Do you have poor digestion } \\
\text { (heartburn, nausea, etc.)? }\end{array}$ & 753 & 72.3 \\
\hline & 3. Do you have lack of appetite? & 222 & 21.3 \\
\hline & 4. Do you have frequent headaches? & 336 & 32.3 \\
\hline & $\begin{array}{l}\text { 5. Have you been crying more than } \\
\text { usual? }\end{array}$ & 518 & 49.8 \\
\hline & 6. Have you been feeling sad lately? & 603 & 57.9 \\
\hline & $\begin{array}{l}\text { 7. Do you feel like a useless, worthless } \\
\text { person? }\end{array}$ & 179 & 17.2 \\
\hline & $\begin{array}{l}\text { 8. Do you feel incapable of playing a } \\
\text { useful role in your life? }\end{array}$ & 171 & 16.4 \\
\hline & 9. Have you lost interest in things? & 341 & 32.8 \\
\hline \multirow{4}{*}{ Scores of the SRQ items: } & 0 to 1 item & 221 & 21.2 \\
\hline & 2 to 3 items & 344 & 33.0 \\
\hline & 4 to 6 items & 367 & 35.3 \\
\hline & 7 to 9 items & 109 & 10.5 \\
\hline \multicolumn{2}{|l|}{ Common mental disorder } & 476 & 45.7 \\
\hline \multirow{5}{*}{ Fear of COVID-19 Scale } & 0 item & 75 & 7.2 \\
\hline & 1 item & 112 & 10.8 \\
\hline & 2 items & 223 & 21.4 \\
\hline & 3 items & 448 & 43.0 \\
\hline & 4 items & 183 & 17.6 \\
\hline
\end{tabular}


feelings towards COVID-19 showed a CMD risk gradient as the number of positive responses increased, going from a prevalence ratio of 1.52 (95\%CI: 1.13-2.04) for women who had two positive items against one or none to 2.70 (95\%CI: $2.08-3.51$ ) for those who had four positive items. The wish to talk to a professional about feelings and thoughts was another condition associated with a higher prevalence of CMD (PR = 1.95; $\mathrm{p}<0.001$ ) (Table 2).

Regarding demographic and socioeconomic determinants, age was associated with the prevalence of CMD, with pregnant women younger than 35 years showing a $21 \%$ higher prevalence $(\mathrm{PR}=1.21 ; 95 \% \mathrm{CI}: 1.01-1,45 ; \mathrm{p}=0.037)$. Pregnant women with 12 years or less of formal education had an $18 \%$ higher risk of CMD prevalence compared to pregnant women with higher education ( $\mathrm{PR}=1.18$; 95\%CI: 1.02-1.38; $\mathrm{p}=0.039$ ). Regarding marital status, pregnant women without a partner had a $37 \%$ higher prevalence of CMD than those with a partner ( $\mathrm{PR}=1.37 ; 95 \% \mathrm{CI}: 1.16-1.61 ; \mathrm{p}=0.003)$, a finding similar to those who lived in households with four or more residents (PR=1.28; 95\%CI: 1.06-1.54; $\mathrm{p}=0.031$ ). Finally, pregnant women that worked outside the home had an $18 \%$ lower prevalence of CMD, when compared with those who did not work $(\mathrm{p}=0.043)($ Table 3$)$.

Regarding the gestational period and prenatal care, pregnant women who were in the $1^{\text {st }}$ and $2^{\text {nd }}$ trimesters of pregnancy had a $32 \%$ and $18 \%$ higher CMD prevalence, respectively, when compared with those in the $3^{\text {rd }}$ trimester $(p=0.005)$. A higher CMD prevalence was

Table 2. Common mental disorders in pregnant women, according to feelings towards COVID-19 during social distancing. Fortaleza, Brazil, 2020.

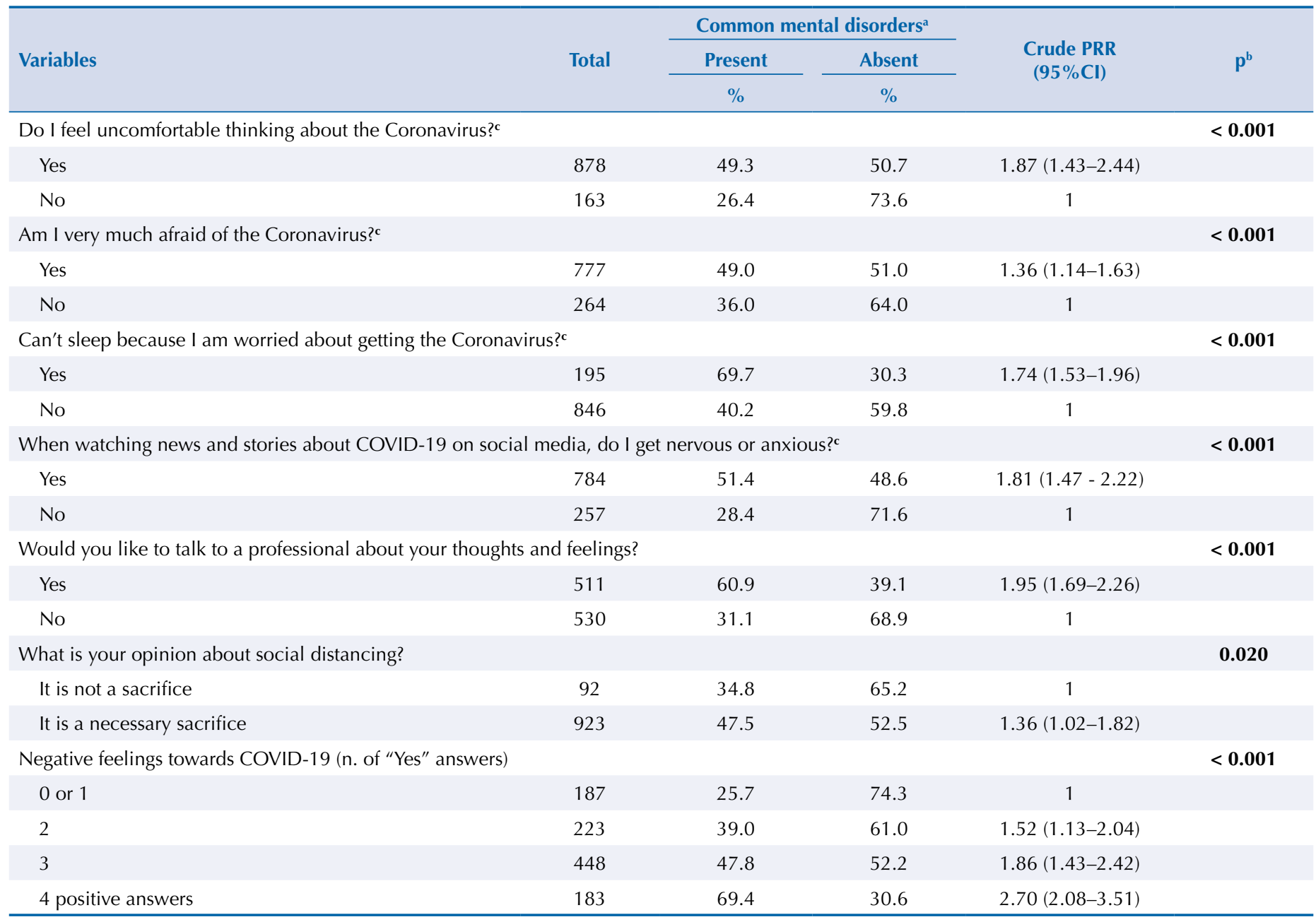

PRR: Prevalence rate ratio.

a Adapted from the SRQ20 scale.

${ }^{\mathrm{b}}$ Chi-square test.

"Adapted from "Fear of COVID-19 Scale" (Ahorsu et al. ${ }^{13}, 2020$ ).

Note: Values with statistical significance are shown in bold. 
Table 3. Common mental disorders in pregnant women experiencing social distancing, according to demographic, socioeconomic, and prenatal care characteristics. Fortaleza, Brazil, 2020.

\begin{tabular}{|c|c|c|c|c|c|}
\hline \multirow{3}{*}{ Variables } & \multirow{3}{*}{ Total } & \multicolumn{2}{|c|}{ Common Mental Disorders ${ }^{a}$} & \multirow{3}{*}{$\begin{array}{c}\text { Crude PRR } \\
(95 \% \mathrm{Cl})\end{array}$} & \multirow{3}{*}{$\mathbf{p}^{\mathbf{b}}$} \\
\hline & & Present & Absent & & \\
\hline & & $\%$ & $\%$ & & \\
\hline \multicolumn{6}{|l|}{ Socioeconomic and demographic variables } \\
\hline \multicolumn{2}{|l|}{ Neighborhood where the woman lives by HDI: } & & & & 0.420 \\
\hline Low HDI (up to 0.49 ) & 571 & 47.5 & 52.5 & $1.09(0.88-1.34)$ & \\
\hline Medium HDI (0.50-0.79) & 317 & 43.2 & 56.8 & $0.99(0.79-1.24)$ & \\
\hline High HDI $(>0.80)$ & 142 & 43.7 & 56.3 & 1 & \\
\hline \multicolumn{2}{|l|}{ Age ranges: } & & & & 0.037 \\
\hline Up to 35 years & 837 & 47.3 & 52.7 & $1.21(1.01-1.45)$ & \\
\hline$>35$ years & 204 & 39.2 & 60.8 & 1 & \\
\hline \multicolumn{2}{|l|}{ Level of schooling: } & & & & 0.039 \\
\hline Up to 12 years of schooling & 203 & 52.2 & 47.8 & $1.18(1.02-1.38)$ & \\
\hline More than 12 years of schooling & 838 & 44.2 & 55.8 & 1.00 & \\
\hline \multicolumn{2}{|l|}{ Marital status: } & & & & 0.003 \\
\hline With a partner & 921 & 43.9 & 56.1 & 1 & \\
\hline Without a partner & 120 & 60.0 & 40.0 & $1.37(1.16-1.61)$ & \\
\hline \multicolumn{2}{|l|}{ Participates in the government's cash transfer program: } & & & & 0.927 \\
\hline Yes & 51 & 45.1 & 54.9 & 1 & \\
\hline No & 990 & 45.8 & 54.2 & $1.01(0.74-1.38)$ & \\
\hline \multicolumn{2}{|l|}{ Works outside the home: } & & & & 0.043 \\
\hline No & 222 & 53.2 & 46.8 & $1.22(1.05-1.41)$ & \\
\hline Yes, before social distancing & 682 & 43.7 & 56.3 & 1.00 & \\
\hline Yes, before and during social distancing & 137 & 43.8 & 56.2 & $1(0.81-1.23)$ & \\
\hline \multicolumn{2}{|l|}{ Number of people living with the pregnant woman: } & & & & 0.031 \\
\hline 0 or 1 person & 351 & 40.5 & 59.5 & 1 & \\
\hline 2 or 3 people & 510 & 47.3 & 52.7 & $1.17(1.00-1.37)$ & \\
\hline 4 or more people & 180 & 51.7 & 48.3 & $1.28(1.06-1.54)$ & \\
\hline \multicolumn{6}{|l|}{ Gestational and assistance variables } \\
\hline \multicolumn{2}{|l|}{ Gestational period: } & & & & 0.005 \\
\hline $1^{\text {st }}$ trimester & 190 & 53.7 & 46.3 & $1.32(1.11-1.56)$ & \\
\hline $2^{\text {nd }}$ trimester & 365 & 48.2 & 51.8 & $1.18(1.02-1.38)$ & \\
\hline $3^{\text {rd }}$ trimester & 486 & 40.7 & 59.3 & 1 & \\
\hline \multicolumn{2}{|l|}{ Prenatal appointments: } & & & & $<0.001$ \\
\hline Not attending prenatal appointments & 43 & 67.4 & 32.6 & $1.57(1.26-1.96)$ & \\
\hline In a basic health unit & 139 & 56.1 & 43.9 & $1.31(1.11-1.54)$ & \\
\hline In a private medical office/ health insurance office & 859 & 43.0 & 57.0 & 1 & \\
\hline \multicolumn{2}{|c|}{ Does someone accompany you at the prenatal appointments? } & & & & 0.542 \\
\hline Goes alone & 282 & 47.2 & 52.8 & $1.06(0.91-1.23)$ & \\
\hline Child's father/partner & 695 & 44.5 & 55.5 & 1 & \\
\hline Mother & 33 & 54.5 & 45.5 & $1.23(0.89-1.69)$ & \\
\hline Other & 31 & 51.6 & 48.4 & $1.16(0.82-1.65)$ & \\
\hline \multicolumn{3}{|c|}{ Did you stop having prenatal consultations during the social distancing period? } & & & 0.017 \\
\hline Yes & 259 & 52.1 & 47.9 & $1.20(1.04-1.38)$ & \\
\hline No & 782 & 43.6 & 56.4 & 1 & \\
\hline \multicolumn{2}{|l|}{ Do you have another child aged 1 to 6 years? } & & & & 0.636 \\
\hline Yes & 303 & 46.9 & 53.1 & $1.04(0.9-1.2)$ & \\
\hline No & 738 & 45.3 & 54.7 & 1 & \\
\hline \multicolumn{2}{|l|}{ Does the child's father live in the same house? } & & & & 0.013 \\
\hline Yes & 924 & 44.2 & 55.8 & 1 & \\
\hline Right now he is living in another house & 43 & 53.5 & 46.5 & $1.21(0.91-1.62)$ & \\
\hline No & 74 & 60.8 & 39.2 & $1.38(1.13-1.68)$ & \\
\hline
\end{tabular}

PRR: Prevalence rate ratio.

adapted from the SRQ20 scale.

${ }^{b}$ Chi-square test.

Note: Values with statistical significance are shown in bold. 
observed among women that had no prenatal consultation ( $\mathrm{PR}=1.57$; 95\%CI: 1.26-1.96; $\mathrm{p}<0.001$ ), whose prenatal care was interrupted ( $\mathrm{PR}=1.20$; 95\%CI: 1.04-1.38; $\mathrm{p}=0.017$ ), and who declared that the child's father did not live in the same household ( $\mathrm{PR}=1.38$; 95\%CI: $1.13-1.68 ; p=0.013$ ) (Table 3).

After the multivariate adjustment, a statistically significant risk gradient adjusted for CMD was observed for pregnant women with negative feelings towards COVID-19. The more negative feelings reported, the greater the CMD prevalence, reaching an adjusted PR of 3.15 (95\%CI: $2.22-4.46 ; \mathrm{p}<0.001$ ) for those with four positive responses. Moreover, an 84\% adjusted risk was observed in participants that were not undergoing prenatal care $(\mathrm{p}=0.007)$ and of $32 \%$ higher among those who had consultations in public health units $(\mathrm{p}=0.042)$ when compared with those who had consultations in private health units. Women in the $1^{\text {st }}$ trimester of pregnancy had a significantly higher CMD prevalence than those in the $3^{\text {rd }}$ trimester ( $\mathrm{PR}=1.43 ; 95 \% \mathrm{CI}: 1.10-1.85 ; \mathrm{p}=0.008)$. A higher $\mathrm{CMD}$ prevalence was also found among pregnant women living with four or more people $(\mathrm{p}=0.028)$, with a $36 \%$ higher adjusted risk than those living with up to one resident. Pregnant women that wished to talk to the health professional about their thoughts and feelings had a 2.3-fold higher CMD prevalence $(\mathrm{p}<0.001)$. Working outside the home had a protective effect, with pregnant women in this condition showing a $21 \%$ lower CMD probability, compared to housewives $(\mathrm{p}=0.037)($ Table 4 and Figure 1$)$.

Table 4. Factors associated with common mental disorders ${ }^{\mathrm{a}}$ in pregnant women during the social distancing period. Fortaleza, Brazil, 2020.

\begin{tabular}{|c|c|c|c|}
\hline Variables & Adjusted PRR & $95 \% \mathrm{Cl}$ & $\mathbf{p}$ \\
\hline \multicolumn{4}{|l|}{ Score of negative feelings towards COVID-19: } \\
\hline 4 positive answers & 3.15 & $2.22-4.46$ & $<0.001$ \\
\hline 3 positive answers & 1.93 & $1.4-2.65$ & $<0.001$ \\
\hline 2 positive answers & 1.52 & $1.07-2.17$ & 0.021 \\
\hline 0 or 1 & 1 & & \\
\hline \multicolumn{4}{|l|}{ Number of people living with the pregnant woman: } \\
\hline 4 or more people & 1.36 & $1.03-1.78$ & 0.028 \\
\hline 2 or 3 people & 1.20 & $0.96-1.49$ & 0.105 \\
\hline 0 or 1 person & 1 & & \\
\hline \multicolumn{4}{|l|}{ Situation of antenatal care: } \\
\hline Not attending & 1.84 & $1.19-2.85$ & 0.007 \\
\hline Attends at the basic health unit & 1.32 & $1.01-1.73$ & 0.042 \\
\hline Attends at a private/medical insurance office & 1 & & \\
\hline \multicolumn{4}{|l|}{ Works outside the home: } \\
\hline Yes & 0.79 & $0.63-0.99$ & 0.037 \\
\hline No & 1 & & \\
\hline \multicolumn{4}{|l|}{ Gestational period: } \\
\hline $1^{\text {st }}$ trimester & 1.43 & $1.10-1.85$ & 0.008 \\
\hline $2^{\text {nd }}$ trimester & 1.17 & $0.94-1.44$ & 0.155 \\
\hline $3^{\text {rd }}$ trimester & 1 & & \\
\hline \multicolumn{4}{|c|}{ Do you wish to talk to a professional about your feelings? } \\
\hline Yes & 2.30 & $1.89-2.8$ & $<0.001$ \\
\hline No & 1 & & \\
\hline
\end{tabular}

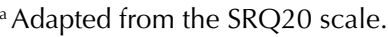

${ }^{b}$ Cox regression model, controlled for the following factors: place of residence, age range, schooling, marital status, and living or not with the child's father.

c Adapted from the Fear of COVID-19 Scale (Ahorsu et al. ${ }^{13}, 2020$ ).

Note: Values with statistical significance are shown in bold. 
4 negative feelings about COVID-19

3 negative feelings about COVID-19

2 negative feelings about COVID-19

None or 1 negative feeling about COVID-19 (ref.)

(Yes) Willing to talk to a professional about feelings (No) Not willing to talk to a professional about feelings (ref.)

Not receiving prenatal care

Receiving prenatal care in a basic health unit Receiving prenatal care in a private clinic (ref.)

1st trimester of pregnancy

2nd trimester of pregnancy

3rd trimester of pregnancy (ref.)

Living with 4 or more people

Living with 2 or 3 people

Living alone or with only one person (ref.)

Working outside the home

Not working outside the home (ref.)

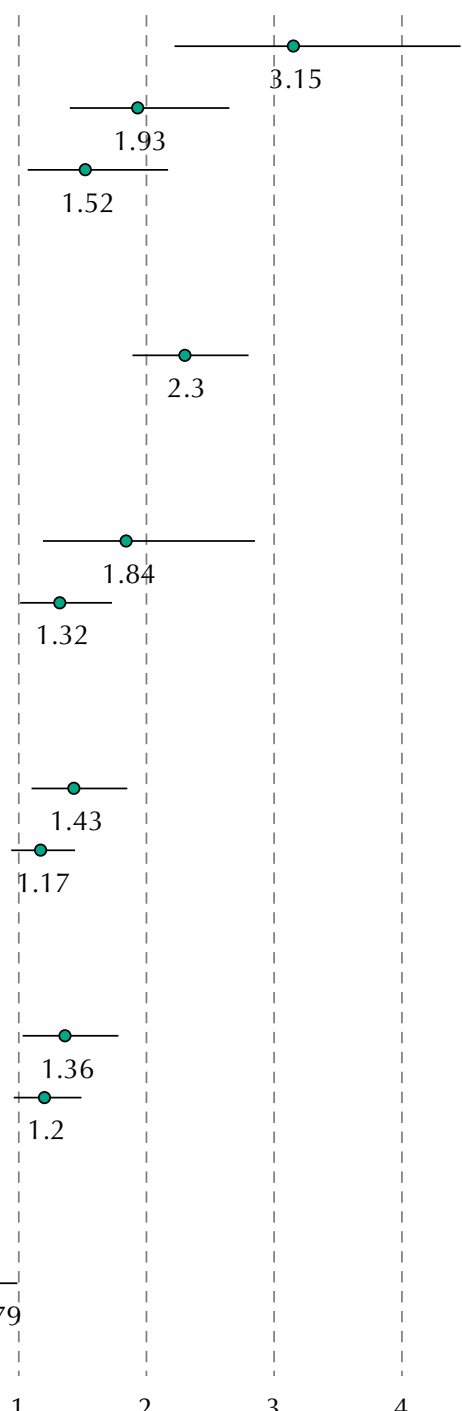

Figure. Forest plot of adjusted estimates of common mental disorders determinants in pregnant women.

\section{DISCUSSION}

We conducted a cross-sectional study with 1,041 pregnant women in a low-income context, in the state of Ceará, Northeastern Brazil, and observed that negative feelings towards COVID-19 increase the CMD prevalence among pregnant women by three times. A higher CMD prevalence was associated with not receiving prenatal care, gestational age, and the number of residents in the household.

Our study showed a $45.7 \%$ (95\%CI: 42.7-48.8) prevalence of CMD in pregnant women in Fortaleza (one of the three cities in Brazil with the highest number of COVID-19 cases, located in the impoverished Northeast region of Brazil), and all items on the Fear of COVID-19 Scale had a strong association with CMD. Although Fortaleza has a high coverage of internet access $(81,4 \%)$, the CMD prevalence found can be even higher among more vulnerable mothers without internet access.

Pregnancy is a time of changes in physical, psychological, family, and social aspects that can trigger feelings of insecurity and affect the mental health of women. We observed that thinking about COVID-19 was the most important item on the fear scale, and it was associated with psychopathological symptoms, such as fear and anxiety. These feelings are expected to increase during the epidemics. For example, during the HIV, Ebola, Zika, and H1N1 outbreaks, fear increased the levels of anxiety both in healthy individuals and in those with pre-existing mental health conditions ${ }^{15}$. A study conducted in West Africa, 
in the post-Ebola epidemic, suggests that the number of individuals whose mental health is affected tends to be greater than the number of infected individuals ${ }^{16}$.

Our results show that watching news and stories about COVID-19 on social media and television can increase the manifestations of negative feelings in pregnant women. Seeking information during crisis events is $\mathrm{common}^{17}$; however, the exposure to a large number of negative news can make people feel anxious and/or distressed ${ }^{18,19}$. In a study on COVID-19 in India, patients recognized that after watching TV programs, listening to radio programs, and reading/watching messages on social media platforms, they developed an intense fear of becoming infected with the new coronavirus ${ }^{20}$. Furthermore, almost a fifth of the pregnant women in other studies reported that negative feelings towards COVID-19 have impaired their sleep, and insomnia has been previously linked to the psychopathological symptoms ${ }^{21-23}$.

The role of gestational age ( $1^{\text {st }}$ trimester of pregnancy), lack of prenatal consultation follow-up, and prenatal care (public health care network) on the CMD prevalence can be explained by two issues. First, the first months of pregnancy are marked by intense hormonal changes that affect the emotional state of the future mother ${ }^{24}$. Second, regular prenatal consultations have been interrupted because both the public and private health care networks are overloaded with care to patients with COVID-1925.

The effects of maternal age ( $<35$ years), education, marital status (not having a partner), number of people in the household (living with four or more people), and not working outside the home during quarantine corroborate previous findings that showed the influence of socioeconomic factors on CMD prevalence ${ }^{6}$.

Our results have important clinical implications, since there is an increased obstetric risk among pregnant women with $\mathrm{CMD}^{23}$. Therefore, in acute cases of negative thoughts and feelings, pregnant women should be advised to seek care from their obstetricians and psychologists, receiving then a better monitoring during the prenatal care, even if remotely ${ }^{8,19}$. When asked about the wish to talk to health professionals during the period of social distancing, $48.9 \%$ of the pregnant women indicated that they felt the need to do so. However, fear of exposure to the coronavirus outside the home implied in many women missing their medical appointments, and local health services did not offer options for home visits or remote care $^{26}$.

Most (92.4\%) pregnant women said that they had adhered to the social distancing strategy and had stayed at home during the pandemic, reporting that it was a "necessary sacrifice" (88.7\%). The social distancing strategy has shown to be one of the best actions to delay the spread of SARS-CoV-2 ${ }^{27-29}$; however, since this measure is gradually being prolonged, the med- and long-term secondary damage caused by social distancing and the symptoms of CMD must be considered in the risk assessment and the care provided to pregnant women ${ }^{30}$.

The selection of the four questions of the Fear of COVID-19 Scale ${ }^{13}$ showed to be suitable for use in Brazil, enabling the verification of differences between groups, and can be used by other national studies. Future studies that follow pregnant women that experienced social distancing and developed CMDs are critical to assess the influence of social distancing on possible obstetric and fetal complications and impaired parental relationships.

Our study has some limitations. First, our data were collected online and thus are not representative of the population of pregnant women, and may particularly underrepresent those who live in conditions of extreme vulnerability and thus do not have access to a smartphone and/or have difficulties filling out the survey. Therefore, our results may provide a best-case scenario of CMD prevalence. Second, we did not use all SRQ questions, since the risk of evoking depressive feelings after reading some questions was considered in a scenario of no feasibility of direct assistance. Moreover, we assessed mental health through questionnaires that are not capable to diagnose mental disease and does not apprehend in depth the feelings and perceptions of the interviewee. 
Our novel study showed that, during the period of social distancing, a high prevalence (45.7\%) of common mental disorders was observed among pregnant women living in a Brazilian city with a high number of COVID-19 cases. These findings call for the development of public policies and clinical protocols aimed at guaranteeing the health of pregnant women during periods of social distancing.

\section{REFERENCES}

1. Dong E, Du H, Gardner L. An interactive web-based dashboard to track COVID-19 in real time. Lancet Infect Dis. 2020;20(5):533-4. https://doi.org/10.1016/S1473-3099(20)30120-1

2. Ministério da Saúde (BR), Secretaria de Vigilância em Saúde. Doença pelo Coronavírus COVID-19. Bol Epidemiol Espec. 2020 [cited 2020 Sep 1];(40):1-75. Available from: https://www.gov.br/saude/pt-br/media/pdf/2020/dezembro/11/boletim_epidemiologico_ covid_40-1.pdf

3. Saccone G, Florio A, Aiello F, Venturella R, De Angelis MC, Locci M, et al. Psychological impact of coronavirus disease 2019 in pregnant women. Am J Obstet Gynecol. 2020;223(2):293-5. https://doi.org/10.1016/j.ajog.2020.05.003

4. Costa DO, Souza FIS, Pedroso GC, Strufaldi MWL. Mental disorders in pregnancy and newborn conditions: longitudinal study with pregnant women attended in primary care. Cienc Saude Coletiva. 2018;23(3):691-700. https://doi.org/10.1590/1413-81232018233.27772015

5. National Collaborating Centre for Mental Health (UK). Common mental health disorders: identification and pathways to care. Leicester (UK): British Psychological Society; 2011.

6. Lucchese R, Simões ND, Monteiro LHB, Vera I, Fernandes IL, Castro PA, et al. Factors associated with the probability of common mental disorders in pregnant women: a cross-sectional study. Esc Anna Nery. 2017;21(3):e20160094. https://doi.org/10.1590/2177-9465-ean-2016-0094

7. Inui $M$, Yokoyama $Y$. [Childcare burdens perceived by mothers with an inter-pregnancy interval less than 12 months]. Nihon Koshu Eisei Zasshi. 2019;66(10):638-48. Japanese. https://dloi.org/10.11236/jph.66.10_638

8. Grigoriadis S, VonderPorten EH, Mamisashvili L, Tomlinson G, Dennis CL, Koren G, et al. The impact of maternal depression during pregnancy on perinatal outcomes: a systematic review and meta-analysis. J Clin Psychiatry. 2013;74(4):e321-41. https://doi.org/10.4088/JCP.12r07968

9. Mate A, Reyes-Goya C, Santana-Garrido A, Vázquez CM. Lifestyle, maternal nutrition and healthy pregnancy. Curr Vasc Pharmacol. 2021;19(2)132-40. https://doi.org/10.2174/1570161118666200401112955

10. Kotabagi P, Fortune L, Essien S, Nauta M, Yoong W. Anxiety and depression levels among pregnant women with COVID-19. Acta Obstet Gynecol Scand. 2020;99(7):953-4. https://doi.org/10.1111/aogs.13928

11. Vandenbroucke JP, Elm E, Altman DG, Gotzsche PC, Mulrow CD, Pocock SJ, et al. Strengthening the Reporting of Observational Studies in Epidemiology (STROBE): explanation and elaboration. Int J Surg. 2014;12(12):1500-24. https://doi.org/10.1016/j.ijsu.2014.07.014

12. Beusenberg M, Orley JH, compilators; World Health Organization. Division of Mental H. A User's guide to the self reporting questionnaire (SRQ). Geneva: World Health Organization; 1994 [cited 2020 Sep 1]. Available from: https://apps.who.int/iris/ handle/10665/61113

13. Ahorsu DK, Lin CY, Imani V, Saffari M, Griffiths MD, Pakpour AH. The Fear of COVID-19 Scale: development and initial validation. Int J Ment Health Addict. 2020 Mar:1-9. https://doi.org/10.1007/s11469-020-00270-8. Epub ahead of print

14. Barros AJD, Hirakata VN. Alternatives for logistic regression in cross-sectional studies: an empirical comparison of models that directly estimate the prevalence ratio. BMC Med Res Methodol. 2003;3:21. https://doi.org/10.1186/1471-2288-3-21

15. Ornell F, Moura HF, Scherer JN, Pechansky F, Kessler FHP, Diemen L. The COVID-19 pandemic and its impact on substance use: implications for prevention and treatment. Psychiatry Res. 2020;289:113096. https://doi.org/10.1016/j.psychres.2020.113096

16. Reardon S. Ebola's mental-health wounds linger in Africa. Nature. 2015;519(7541):13-14. https://doi.org/10.1038/519013a 
17. Purgato M, Gastaldon C, Papola D, Ommeren M, Barbui C, Tol WA. Psychological therapies for the treatment of mental disorders in low- and middle-income countries affected by humanitarian crises. Cochrane Database Syst Rev. 2018;7:CD011849-CD011849. https://doi.org/10.1002/14651858.CD011849.pub2

18. Wang C, Pan R, Wan X, Tan Y, Xu L, Ho CS, et al. Immediate psychological responses and associated factors during the initial stage of the 2019 coronavirus disease (COVID-19) epidemic among the general population in China. Int J Environ Res Public Health. 2020;17(5):1729. https://doi.org/10.3390/ijerph17051729

19. World Health Organization. COVID-19 and the Need for Action on Mental Health. Policy brief. Geneva $(\mathrm{CH})$ : WHO; 2020.

20. Kumar A, Somani A. Dealing with Corona virus anxiety and OCD. Asian J Psychiatr. 2020;51:102053. https://doi.org/10.1016/j.ajp.2020.102053

21. Pappa S, Ntella V, Giannakas T, Giannakoulis VG, Papoutsi E, Katsaounou P. Prevalence of depression, anxiety, and insomnia among healthcare workers during the COVID-19 pandemic: a systematic review and meta-analysis. Brain Behav Immun. 2020;88:901-7. https://doi.org/10.1016/j.bbi.2020.05.026

22. Torales J, O'Higgins M, Castaldelli-Maia JM, Ventriglio A. The outbreak of COVID-19 coronavirus and its impact on global mental health. Int J Soc Psychiatry. 2020;66(4):317-20. https://doi.org/10.1177/0020764020915212

23. Wu Y, Zhang C, Liu H, Duan C, Li C, Fan J, et al. Perinatal depressive and anxiety symptoms of pregnant women during the coronavirus disease 19 outbreak in China. Am J Obstet Gynecol. 2020;223(2):240.e1-240.e9. https://doi.org/10.1016/j.ajog.2020.05.009

24. Soma-Pillay P, Nelson-Piercy C, Tolppanen H, Mebazaa A. Physiological changes in pregnancy. Cardiovasc J Afr. 2016;27(2):89-94. https://doi.org/10.5830/CVJA-2016-021

25. Faure-Bardon V, Salomon LJ, Leruez-Ville M, Ville Y. How should we treat pregnant women infected with SARS-CoV-2? BJOG. 2020;127(9):1050-2. https://doi.org/10.1111/1471-0528.16270

26. Rashid Fakari F, Simbar M. Coronavirus pandemic and worries during pregnancy; a letter to editor. Arch Acad Emerg Med. 2020;8(1):e21. https://doi.org/10.22037/aaem.v8i1.598

27. Banerjee D, Rai M. Social isolation in Covid-19: the impact of loneliness. Int J Soc Psychiatry. 2020;66(6):525-7. https://doi.org/10.1177/0020764020922269

28. Malay DS. COVID-19, pandemic, and social distancing. J Foot Ankle Surg. 2020;59(3):447-8. https://doi.org/10.1053/j.jfas.2020.03.010

29. Nicol GE, Piccirillo JF, Mulsant BH, Lenze EJ. Action at a distance: geriatric research during a pandemic. J Am Geriatr Soc. 2020;68(5):922-5. https://doi.org/10.1111/jgs.16443

30. Plagg B, Engl A, Piccoliori G, Eisendle K. Prolonged social isolation of the elderly during COVID-19: between benefit and damage. Arch Gerontol Geriatr. 2020;89:104086. https://doi.org/10.1016/j.archger.2020.104086

Funding: Fundação Maria Cecilia Souto Vidigal, 2020.

Authors' Contributions: Study design and planning: MMTM, HALR, MCC, LLC. Data collection, analysis and interpretation: MMTM, HALR, MCC, LLC, EGMS. Manuscript drafting or review; approval of the final version; and public responsibility for the content of the article: all of the authors.

Conflict of Interests: The authors declare no conflict of interest. 